\title{
Influence of Entrepreneurial Social Capital on Enterprise Growth Performance with Environmental Competitiveness as the Moderating Variable
}

\author{
Liu Shumin ${ }^{1}$, Soon-Bok Hong ${ }^{2}$, Zeng Zishu ${ }^{3}$ \\ ${ }^{1}$ Teacher, Department of Business Administration, Hunan University of Technology Hunan China, \\ China,604187@qq.com \\ ${ }^{2}$ Professor, Department of Business Administration, Tongmyong University, South Korea, \\ hong6601@hanmail.net \\ ${ }^{3}$ Student, Department of Mass communication \& Advertising, Tongmyong University, South Korea, \\ shuzi1031@naver.com
}

Corresponding author: Liu Shumin

\begin{abstract}
From a management perspective, entrepreneurial social capital obtains scarce resources by establishing contacts with the more appropriate term, which in turn affects corporate performance. However, existing research has not conducted in-depth research on the path of entrepreneurial social capital affecting corporate growth performance. Empirical research is also relatively scarce. According to the theory of social capital, and the results of prior studies, the social capital of entrepreneurship was divided into three aspects: the social capital of the entrepreneur system, the social capital of the entrepreneur's business, and the social capital of the entrepreneur's technology. This paper focused on the relationship mechanism between the entrepreneur's social capital and the company's growth performance, and constructed the theoretical model by introducing the environmental competitiveness into the action path of entrepreneurial social capital to enterprise growth performance. On this basis, 350 smes in Hunan, Hubei, Jiangxi, Guangdong and other provinces of China were empirically studied through a survey. This paper used the SPSS25.0 to analyze the valid data. The empirical results show that there is a significant positive correlation between firm growth performance and entrepreneur institutional social capital, entrepreneur technological social capital, and environmental competitiveness. The study also found that, environmental competitiveness plays a positive role in regulating The relationship between entrepreneurial business social capital and enterprise growth performance, that is, environmental competitiveness can strengthen the impact of it on enterprise growth performance. Environmental competitiveness has no moderating effect between entrepreneurial commercial social capital, entrepreneurial technological social capital, and enterprise growth performance.Through research, it can be learned that entrepreneurs should pay attention to the importance of social capital to corporate growth and performance improvement, strengthen the cultivation of entrepreneur' awareness of interconnection and cooperation with external parties, actively expand their own social networks, and attract a wider range of social capital. At the same time, in the complex and fierce market competition, entrepreneurs should pay more attention to the expansion and maintenance of entrepreneurs' commercial social capital.
\end{abstract}

Keywords: Entrepreneurial Social Capital, Enterprise Growth Performance, Environmental Competitiveness

Received: May 23, 2021; $1^{\text {st }}$ Review Result: July 08, 2021; $2^{\text {nd }}$ Review Result: August 25, 2021 Accepted: September 30, 2021 


\section{Introduction}

The global economy has entered a new era, giving birth to the development of communication networks based on the revolution of information technology, networking, and innovation as the main content, and the social structure and economic environment had fundamental changes. In the era of information and knowledge economy, the technological and financial resources accumulated by enterprises themselves can no longer meet the needs of the rapidly changing market environment, and the competitive advantage of enterprises also depends on their ability to obtain resources from outside to a large extent. Research has found that the integration of internal and external resources of the enterprise and the social network of entrepreneurs has an important influence on the growth of the enterprise[1]. When seeing from the perspective of this, entrepreneurs can transform external key resources into the resources needed for enterprise development, and become the key bridge connecting enterprises with external resources. Therefore, we regard entrepreneurial it as one of the important strategic resources of enterprises to make up for the limitation of enterprise resources. Entrepreneurs it in the resources needed to bring business development at the same time, also to a certain extent, affect the enterprise performance[2]. Although there are many researches concerning the entrepreneurs affecting the corporate performance, the existing research of it and enterprise growth performance internal influence mechanism mechanism lack in-depth discussion and relevant relevant empirical research. Therefore, this paper takes this as an entry point to explore the effect of it on enterprise growth performance and the path mechanism of the effect.

Considering that enterprises do not exist in isolation in the society, the process of enterprise growth is a process of continuous running with the external environment. In the running-in, enterprises constantly adjust the existing management, technology, innovation, sales and other aspects to adapt to the needs of the environment. In this context, scholars have introduced the study of environmental competitiveness, which refers to the intensity of external environmental competition, mainly reflected by the degree of enterprises facing threats from competitors and the intensity of current competition[3]. Although for enterprises, environmental competition is more of a kind of pressure, which brings business risks and decision-making anxiety to enterprises, it may also become an opportunity for enterprises to make breakthroughs in development. By coordinating and deploying internal and external resources of enterprises, it can maintain or realize the growth of enterprise performance. Considering the impact of environmental competitiveness on firm performance, whether environmental competitiveness will play a moderating role between entrepreneurs' social capital and firm growth performance naturally becomes the key point to be discussed in this study. Based on this, the purpose of this study is to examine the path mechanism of the impact of it on enterprise growth performance. Environmental competitiveness is innovatively introduced as a moderating variable to analyze its mechanism, so as to provide an important reference and basis to explore the path mechanism of the impact of it on enterprise growth performance.

\section{Theoretical Background}

Concept definition is very important to the study of it . There are various concepts of it because scholars have not formed a consensus on its concept. There are mainly four categories, including resources, networks, capabilities, and multiple perspectives. This paper agrees with the viewpoint of Westlund and Bolton, and thinks that entrepreneurial social capital itself is a kind of invisible network resources, which are not only the total sum of all social relations that can be utilized and transferred and embedded in the entrepreneurial social network, but also an ability owned by entrepreneurs to use its relations in social networks to obtain scarce resources[4]. The research on this, especially the empirical research, needs to distinguish its dimensions before it can proceed. Peng and Luo put forward the 
concept of entrepreneurial political social capital or entrepreneurial institutional social capital[5]. Subsequently, many scholars adopted this view and divided the entrepreneurial social capital into three aspects, including entrepreneurial institutional social capital, entrepreneurial commercial social capital, as well as entrepreneurial technological social capital. Entrepreneurial institutional social capital is the relationship network established by entrepreneurs with government officials at all levels, supervision departments or other administrative organs, and the financial sector such as banks. Entrepreneurial commercial social capital refers to the social network formed by the connections between entrepreneurs and suppliers, customers, cooperative manufacturers, and competitors. Entrepreneurial technological social capital refers to the relationship network established by entrepreneurs with technical experts of universities and research institutions, personnel of technical intermediaries such as national or local engineering technology centers, as well as industrial technical experts of other enterprises[6][7].

Enterprise growth performance is an important part of enterprise performance, which mainly measures the performance of an enterprise in terms of growth. As for the concept of enterprise growth performance, researchers both at home and abroad have defined it from different perspectives. Most of them believe that growth performance focuses on the development ability and growth potential of an enterprise, including both the expansion of organizational scale and the increase of profitability. Olson and Bokor hold that enterprise growth performance is the growth of organizational ability and the expansion of market scope, as well as the performance that an enterprise continuously improves its survival ability in a dynamic environment[8]. Chaganti believes that the growth of an enterprise must be based on certain internal resources, and the improvement of growth performance is manifested as the expansion of scale and the improvement of revenue creating ability, and the key is whether an enterprise can make the most effective use of existing resources[9]. Jiang Yuewei thinks that enterprise growth performance is the result of corresponding strategic decisions made by entrepreneurs based on different influencing factors, such as enabling enterprises to achieve internal progress and promoting the growth of external efficiency[10].

Ettlie and Bridges believe that environmental competitiveness refers to the degree of fierce environmental competition perceived by enterprises subjectively or objectively, and the cruelty of the competitive environment is closely correlated with the innovation enthusiasm of organizations[11]. Jansen thinks that environmental competitiveness refers to the existing degree of competition in the environment, which is reflected in the number of competitors as well as the number of regions where competition exists. A highly competitive environment is often associated with stronger competitive pressure, such as higher efficiency and lower price, and leads to less marginal profit[12]. Baron and Tang suggest that environmental competitiveness refers to the intensity of resource competition in the external environment. Enterprises can enjoy these resources in the environment, but these resources will also be competed for by some factors in the environment and other enterprises[13].

\section{Research Methods}

\subsection{Theoretical Framework and Research Hypothesis}

Based on the theory of social capital, this paper divides the social capital of entrepreneurs into three dimensions, namely institutional social capital of entrepreneurs, commercial social capital of entrepreneurs and technological social capital of entrepreneurs, after reading and sorting out the previous research results, focus on the mechanism of its relationship with corporate growth performance, and introduce environmental competitiveness into the limit value of its impact on corporate growth performance. Besides, the basic assumptions contained in the model were proposed, as shown in [Fig. $1]$. 


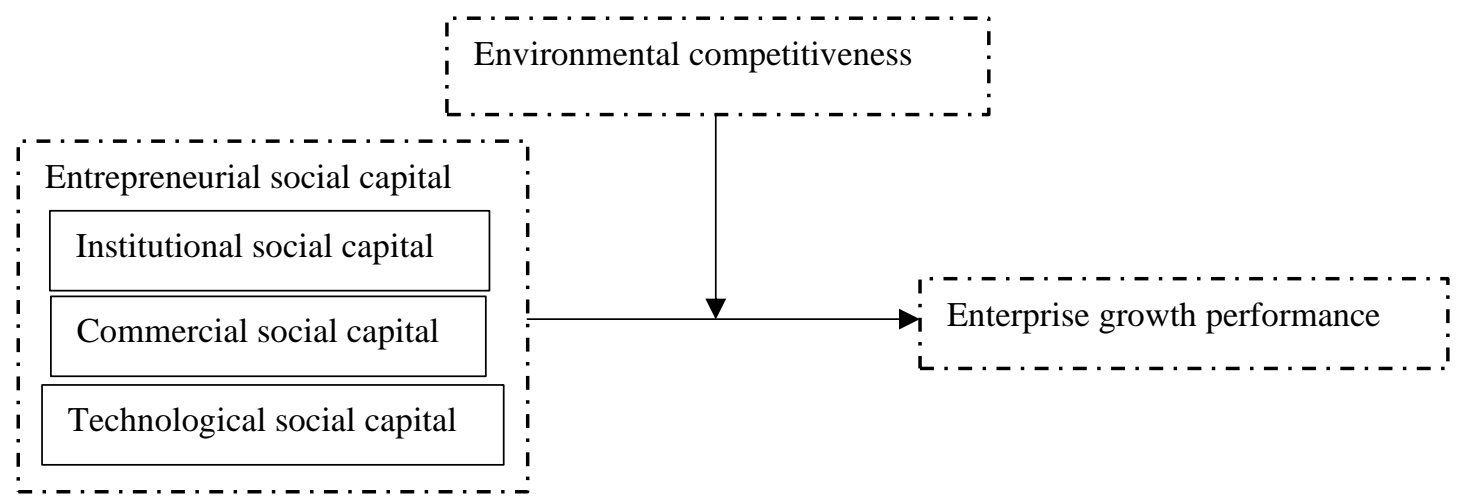

[Fig. 1] Theoretical Framework

On the basis of the above theoretical basis and precedent, hypothesis 1 and hypothesis 2 are propose.

[Table 1] Summary of Research Hypotheses

\begin{tabular}{|l|l|}
\hline H1 & Entrepreneurial social capital is related to enterprise growth performance \\
\hline $1-1$ & Entrepreneurial institutional social capital is related to enterprise growth performance \\
\hline $1-2$ & Entrepreneurial commercial social capital is related to enterprise growth performance \\
\hline $1-3$ & Entrepreneurial technological social capital is related to enterprise growth performance \\
\hline H2 & $\begin{array}{l}\text { Environmental competitiveness plays a moderating role in the relationship between } \\
\text { entrepreneurial social capital and enterprise growth performance }\end{array}$ \\
\hline $2-1$ & $\begin{array}{l}\text { Environmental competitiveness plays a moderating role in the relationship between } \\
\text { entrepreneurial institutional social capital and enterprise growth performance }\end{array}$ \\
\hline $2-2$ & $\begin{array}{l}\text { Environmental competitiveness plays a moderating role in the relationship between } \\
\text { entrepreneurial commercial social capital and enterprise growth performance }\end{array}$ \\
\hline $2-3$ & $\begin{array}{l}\text { Environmental competitiveness plays a moderating role in the relationship between } \\
\text { entrepreneurial technological social capital and enterprise growth performance }\end{array}$ \\
\hline
\end{tabular}

\subsection{Sample Collection and Variable Measurement}

To overcome the problem that sample information may be inaccurate in the research process, the main research objects are small and medium-sized enterprises in China.The survey area of the questionnaire is mainly concentrated in the small and medium-sized enterprises in Hunan, Hubei, Jiangxi, and Guangdong provinces of China. The survey process of the questionnaire started on November 20, 2020 to January 15, 2021, and lasted for 55 days. In this study, 450 surveys were distributed and 382 were recovered, of which 350 were valid and 32 were invalid. The main reasons for the ineffectiveness of the questionnaire were that the fill rate of the questionnaire was less than $70 \%$ and the answers were almost identical, which accounted for $8 \%$ of the questionnaires returned. Then, the valid responses were analyzed using SPSS25.0. In the process of questionnaire filling, as the COVID19 in 2019 has caused great losses to many small and medium-sized enterprises, and to avoid data distortion caused by this global epidemic, the enterprise growth performance before the outbreak of the epidemic was mainly studied. Therefore, when entrepreneurs filled in the questionnaire, they were asked to fill in the questionnaire according to the enterprise performance before the outbreak of the epidemic.

From the perspective of gender, the sample of this survey is more on males, 197 individuals, accounting for $56 \%$, and 153 are females, accounting for $44 \%$. Based on age, the samples were concentrated between 18 and 39 years old, with a total of 197 individuals. In terms of education level, 144 people in the sample have college degree or above, accounting for $41 \%$.Among the respondents in 
this survey, 253 of them are non-high-tech industries, accounting for $72 \%$,which is relatively high.In terms of working years, 126 people have worked for $1-5$ years, accounting for $36 \% .124$ people have worked for 5 to 10 years, accounting for 35\%; In terms of the number of years of company establishment, 106 companies were established 1-5 years ago, accounting for 30\%.92 companies were established for 5 to 10 years, accounting for $26 \%$.In terms of the number of employees, $50 \%$ of enterprises have less than 50 employees, and there are 103 enterprises with 50 employees --100 employees, accounting for $30 \%$.In terms of annual sales, there are 19 companies with annual sales of less than 100 million KRW, accounting for $5 \% .42$ companies with annual sales of 100 million won to 500 million won, accounting for 12\%;152 companies with annual sales between 500 million won and 1 billion won, accounting for $43 \%$;93 companies with annual sales between 1 billion won and 1.5 billion won, accounting for $27 \%$; There are 44 companies with annual sales of more than 1.5 billion won, accounting for $13 \%$.

[Table 2] Descriptive Statistical Analysis of Human Demography

\begin{tabular}{|c|c|c|c|}
\hline & & Count & Column N \% \\
\hline \multirow{2}{*}{ Gander } & Male & 197 & $56 \%$ \\
\hline & Female & 153 & $44 \%$ \\
\hline \multirow{6}{*}{ Age } & Under 18 years old & 23 & $7 \%$ \\
\hline & $18-29$ & 95 & $27 \%$ \\
\hline & $30-39$ & 102 & $29 \%$ \\
\hline & $40-49$ & 53 & $15 \%$ \\
\hline & $50-59$ & 46 & $13 \%$ \\
\hline & Over 60 years old & 31 & $9 \%$ \\
\hline \multirow{5}{*}{ Educational } & Below senior high school & 30 & $9 \%$ \\
\hline & Senior high school & 176 & $50 \%$ \\
\hline & Junior college & 37 & $10 \%$ \\
\hline & Undergraduate & 52 & $15 \%$ \\
\hline & Graduate or above & 55 & $16 \%$ \\
\hline \multirow{2}{*}{ 4. Industry } & High-tech industry & 97 & $28 \%$ \\
\hline & Non-high-tech industry & 253 & $72 \%$ \\
\hline \multirow{4}{*}{ 5. Years of leadership } & Less than 1 year & 39 & $11 \%$ \\
\hline & $1-5$ & 126 & $36 \%$ \\
\hline & $5-10$ & 124 & $35 \%$ \\
\hline & More than 10 years & 61 & $18 \%$ \\
\hline \multirow{4}{*}{ 6. Years of establishment } & Less than 1 year & 83 & $24 \%$ \\
\hline & $1-5$ & 106 & $30 \%$ \\
\hline & $5-10$ & 92 & $26 \%$ \\
\hline & More than 10 years & 69 & $20 \%$ \\
\hline \multirow{5}{*}{ 7. Number of employees } & Less than 50 & 172 & $49 \%$ \\
\hline & $50-100$ & 103 & $30 \%$ \\
\hline & $100-150$ & 42 & $12 \%$ \\
\hline & $150-200$ & 18 & $5 \%$ \\
\hline & More than 200 & 15 & $4 \%$ \\
\hline \multirow{5}{*}{ 8. Annual sales } & Less than 600,000 & 19 & $5 \%$ \\
\hline & $600,000-3,000,000$ & 42 & $12 \%$ \\
\hline & $3,000,000-6,000,000$ & 152 & $43 \%$ \\
\hline & $6,000,000-9,000,000$ & 93 & $27 \%$ \\
\hline & More than $9,000,000$ & 44 & $13 \%$ \\
\hline
\end{tabular}

In this paper, the measurement questions of Guo Lixin , Wu Junjie[14][15] were used, and 21 questions were adopted to measure entrepreneurial institutional social capital, social business capital, and sociotechnical capital. The measurement questions of Antoncic , Bruton, Ji Lingling[16-18] for enterprise growth performance, and seven questions were used for measurement. Referring to the measurement items of environmental competitiveness[19][20], this paper adopted seven items for measurement. 


\section{Empirical Analysis}

\subsection{Validity and Reliability of Variables}

Through reliability analysis, it is found that the Cronbach's Alpha coefficients of all dimensions are all greater than 0.8 , so from the data of the scale, it can be known that the internal consistency between each item is relatively good, and the sample has high reliability.

It can be seen from the [Table 3], that the common degree values of the research items are all greater than 0.4 , and the KMO value in the scale is greater than 0.6 , which is 0.889 . Secondly, the variance explanation rates of the 5 factors are $14.467 \%, 14.366 \%, 14.243 \%, 14.009 \%$, and $11.91 \%$, respectively, and the cumulative variance explanation rate is $69.076 \%>50 \%$. The data in the scale shows that the information in the research project can be used. Effective extraction. Therefore, the validity of the questionnaire is very high, and subsequent analysis and research can be carried out.

[Table 3] Factor Analysis Results of Research Variables

\begin{tabular}{|c|c|c|c|c|c|c|c|}
\hline \multirow[b]{2}{*}{ Title } & \multirow{2}{*}{$\begin{array}{c}\text { Commu } \\
\text { nality }\end{array}$} & \multicolumn{5}{|c|}{ Factor name } & \multirow{2}{*}{$\begin{array}{c}\text { Conbac } \\
\text { h's } \\
\text { Alpha }\end{array}$} \\
\hline & & Performance & Technological & Commercial & competitiveness & $\begin{array}{c}\text { Institutiona } \\
1\end{array}$ & \\
\hline Performance1 & 0.826 & 0.889 & & & & & \multirow{4}{*}{0.840} \\
\hline Performance2 & 0.665 & 0.755 & & & & & \\
\hline Performance3 & 0.600 & 0.686 & & & & & \\
\hline Performance4 & 0.677 & 0.790 & & & & & \\
\hline Technological1 & 0.793 & & 0.870 & & & & \multirow{4}{*}{0.841} \\
\hline Technological2 & 0.618 & & 0.724 & & & & \\
\hline Technological3 & 0.634 & & 0.720 & & & & \\
\hline Technological4 & 0.686 & & 0.785 & & & & \\
\hline Commerciall & 0.792 & & & 0.854 & & & \multirow{4}{*}{0.847} \\
\hline Commercial2 & 0.647 & & & 0.745 & & & \\
\hline Commercial3 & 0.660 & & & 0.735 & & & \\
\hline Commercial4 & 0.679 & & & 0.781 & & & \\
\hline Competitiveness1 & 0.804 & & & & 0.800 & & \multirow{4}{*}{0.836} \\
\hline Competitiveness 2 & 0.589 & & & & 0.630 & & \\
\hline Competitiveness 3 & 0.591 & & & & 0.586 & & \\
\hline Competitiveness 4 & 0.701 & & & & 0.731 & & \\
\hline Institutional1 & 0.811 & & & & & 0.882 & \multirow{4}{*}{0.860} \\
\hline Institutional2 & 0.660 & & & & & 0.752 & \\
\hline Institutional3 & 0.713 & & & & & 0.802 & \\
\hline Institutional4 & 0.669 & & & & & 0.763 & \\
\hline \multicolumn{2}{|c|}{ Eigenvalue } & 7.377 & 1.928 & 1.841 & 1.759 & 0.909 & 1 \\
\hline \multicolumn{2}{|c|}{ Variance ratio } & $14.467 \%$ & $14.366 \%$ & $14.243 \%$ & $14.009 \%$ & $11.991 \%$ & 1 \\
\hline \multicolumn{2}{|c|}{$\begin{array}{l}\text { Cumulative proportion of } \\
\text { variance }\end{array}$} & $14.467 \%$ & $28.833 \%$ & $43.076 \%$ & $57.085 \%$ & $69.076 \%$ & / \\
\hline \multicolumn{4}{|c|}{ KMO } & \multicolumn{4}{|c|}{0.889} \\
\hline \multirow{3}{*}{\multicolumn{2}{|c|}{ Bartlett sphericity test }} & \multicolumn{2}{|c|}{ Chi-square } & \multicolumn{4}{|c|}{3042.823} \\
\hline & & \multicolumn{2}{|c|}{ Degree of freedom } & \multicolumn{4}{|c|}{190.000} \\
\hline & & \multicolumn{2}{|c|}{ Significance test } & \multicolumn{4}{|c|}{0.000} \\
\hline
\end{tabular}




\subsection{Relevant Analysis}

This study uses correlation analysis to study the correlation between various variables, and uses Pearson's correlation coefficient to indicate the strength of the correlation. As shown in [Table 4], there is a significant correlation between corporate growth performance and other variables. Specifically, the correlation value between enterprise growth performance and entrepreneurial institutional social capital is 0.524 ; The correlation value between enterprise performance and entrepreneurial commercial social capital is 0.55 ; The value of correlation between enterprise performance and entrepreneurial technological social capital is 0.567 ; The value of correlation between enterprise performance and environmental competitiveness is 0.44 . Therefore, there is a significant positive correlation between enterprise growth performance and entrepreneurial institutional social capital, entrepreneurial commercial social capital, entrepreneurial technological social capital, and environmental competitiveness.

[Table 4] Correlation Analysis among Measurement Variables

\begin{tabular}{|c|c|c|c|c|c|}
\hline Variable & $\begin{array}{l}\text { Institutional } \\
\text { social capital }\end{array}$ & $\begin{array}{l}\text { Commercial } \\
\text { social capital }\end{array}$ & $\begin{array}{l}\text { Technological } \\
\text { social capital }\end{array}$ & $\begin{array}{c}\text { growth } \\
\text { performance }\end{array}$ & $\begin{array}{l}\text { Environmental } \\
\text { competitiveness }\end{array}$ \\
\hline $\begin{array}{l}\text { Institutional social } \\
\text { capital }\end{array}$ & 1 & & & & \\
\hline $\begin{array}{l}\text { Commercial social } \\
\text { capital }\end{array}$ & $0.331^{* * *}$ & 1 & & & \\
\hline $\begin{array}{l}\text { Technological } \\
\text { social capital }\end{array}$ & $0.311^{* * *}$ & $0.357^{* *}$ & 1 & & \\
\hline $\begin{array}{c}\text { growth } \\
\text { performance }\end{array}$ & $0.524^{* *}$ & $0.550^{* * *}$ & $0.567^{* * *}$ & 1 & \\
\hline $\begin{array}{c}\text { Environmental } \\
\text { competitiveness }\end{array}$ & $0.329 * *$ & $0.362^{* * *}$ & $0.369^{* *}$ & $0.440^{* * *}$ & 1 \\
\hline \multicolumn{6}{|c|}{ Note: $* * p<0.01,{ }^{*} \mathrm{p}<0.05$} \\
\hline
\end{tabular}

\subsection{Moderation Effect Test}

As shown in [Table 5], It can be seen that the social capital of the entrepreneurial system has a more obvious predictive effect on the growth performance of the enterprise $(\beta=0.306, p<0.001)$ while entrepreneurial institutional social capital has a significant predictive effect on enterprise growth performance $(\beta=0.321, p<0.001)$; The regression coefficient of the interaction items "entrepreneurial technological social capital * environmental competitiveness", and "entrepreneurial institutional social capital * environmental competitiveness" is not significant, but the regression coefficient of the interaction item "entrepreneurial commercial social capital * environmental competitiveness" is significant $(\beta=0.50, p<0.05)$. In conclusion, environmental competitiveness plays a role in regulating the relationship between entrepreneurial commercial social capital and enterprise growth performance. The regression coefficient of the interaction term "entrepreneurial commercial social capital * environmental competitiveness" is 0.086 , and the two symbols are the same, indicating that environmental competitiveness plays a positive role in regulating its relationship with corporate growth performance, that is, environmental competitiveness can strengthen its effect on corporate growth performance. Environmental competitiveness has no moderating effect between entrepreneurial commercial social capital, entrepreneurial technological social capital, and enterprise growth performance. 
[Table 5] Regulating Results of Enterprise Growth Performance Regression Analysis

\begin{tabular}{|c|c|c|c|c|c|c|c|c|c|}
\hline & \multicolumn{3}{|c|}{ (Model 1) } & \multicolumn{3}{|c|}{ (Model2) } & \multicolumn{3}{|c|}{ (Model3) } \\
\hline & B & $\beta$ & p-Value & B & $\beta$ & p-Value & B & $\beta$ & p-Value \\
\hline (Constant) & 0.359 & & 0.025 & 0.234 & & 0.156 & 1.601 & & 0.012 \\
\hline Institutional social capital & 0.274 & 0.306 & 0.000 & 0.255 & 0.285 & 0.000 & 0.218 & 0.244 & 0.094 \\
\hline Commercial social capital & 0.293 & 0.321 & 0.000 & 0.270 & 0.296 & 0.000 & -0.011 & -0.012 & 0.933 \\
\hline Technological social capital & 0.324 & 0.357 & 0.000 & 0.299 & 0.329 & 0.000 & 0.153 & 0.168 & 0.241 \\
\hline Environmental competitiveness & & & & 0.106 & 0.118 & 0.008 & -0.296 & -0.330 & 0.110 \\
\hline $\begin{array}{c}\text { Institutional social capital* } \\
\text { Environmental competitiveness }\end{array}$ & & & & & & & 0.003 & 0.018 & 0.942 \\
\hline $\begin{array}{l}\text { Commercial social capital * } \\
\text { Environmental competitiveness }\end{array}$ & & & & & & & 0.086 & 0.508 & 0.033 \\
\hline $\begin{array}{l}\text { Technological social capital* } \\
\text { Environmental competitiveness }\end{array}$ & & & & & & & 0.044 & 0.258 & 0.275 \\
\hline R2 & \multicolumn{3}{|c|}{0.539} & \multicolumn{3}{|c|}{0.544} & \multicolumn{3}{|c|}{0.55} \\
\hline $\mathrm{F}$ & \multicolumn{3}{|c|}{115.502} & \multicolumn{3}{|c|}{90.166} & \multicolumn{3}{|c|}{53.23} \\
\hline Significant probability & \multicolumn{3}{|c|}{$0.000 * * *$} & \multicolumn{3}{|c|}{$0.000 * * *$} & \multicolumn{3}{|c|}{$0.000 * * *$} \\
\hline \multicolumn{10}{|c|}{$\mathrm{p}<0.01^{*}, \mathrm{p}<0.05^{* *}, \mathrm{p}<0.001^{* * *}$} \\
\hline
\end{tabular}

\section{Research result and Discussion}

\subsection{Summary of Research Hypothesis}

The regression analysis was carried out through SPSS25.0 to verify the six hypotheses proposed above, and the specific summary results are shown in [Table 6].

[Table 6] Summary of Research Hypothesis

\begin{tabular}{|c|l|c|}
\hline \multicolumn{2}{|c|}{ Research hypothesis } & $\begin{array}{c}\text { The verification } \\
\text { results }\end{array}$ \\
\hline $1-1$ & $\begin{array}{l}\text { Entrepreneurial institutional social capital is related to enterprise growth } \\
\text { performance }\end{array}$ & Is accepted \\
\hline $1-2$ & $\begin{array}{l}\text { Entrepreneurial commercial social capital is related to enterprise growth } \\
\text { performance }\end{array}$ & Is accepted \\
\hline $1-3$ & $\begin{array}{l}\text { Entrepreneurial technological social capital is related to enterprise growth } \\
\text { performance }\end{array}$ & $\begin{array}{l}\text { Environmental competitiveness plays a moderating role in the relationship between } \\
\text { entrepreneurial institutional social capital and enterprise growth performance }\end{array}$ \\
\hline $2-2$ & $\begin{array}{l}\text { Environmental competitiveness plays a moderating role in the relationship between } \\
\text { entrepreneurial commercial social capital and enterprise growth performance }\end{array}$ & Is not accepted \\
\hline $2-3$ & $\begin{array}{l}\text { Environmental competitiveness plays a moderating role in the relationship between } \\
\text { entrepreneurial technological social capital and enterprise growth performance }\end{array}$ & Is not accepted \\
\hline
\end{tabular}


According to the results there is a significant positive correlation between entrepreneurial social capital and corporate performance, entrepreneur commercial social capital and entrepreneur technical social capital. which indicates that each dimension of entrepreneurial social capital significantly affects the growth performance of enterprises. This research conclusion is consistent with the conclusion drawn by Smith and Jiang Chunyan et al.[1][2]. The three dimensions of entrepreneurs' social capital are important sources for enterprises to obtain resources, information, contacts, etc. Through this access channel, the growth performance of enterprises can be effectively improved.

According to the results of the study environmental competitiveness does not significantly regulate the social capital of the entrepreneurial system, the social capital of entrepreneurial technology, and the growth performance of enterprises. The environmental competitiveness has a positive moderating effect on the relationship between entrepreneurial commercial social capital and corporate growth performance, that is, environmental competitiveness can strengthen the impact of entrepreneurial commercial social capital on enterprise growth performance. This shows that in the complex and fierce market competition, environmental competitiveness plays a positive role in regulating entrepreneurs' commercial social capital. The business cooperation resources with suppliers, distributors, customers, competitors in the same industry, and partners contained in entrepreneurs' business social capital can promote the growth performance of enterprises.

\section{Conclusion}

This paper aims to empirically study whether there is a correlation between entrepreneurial social capital and corporate performance, and the moderating role of environmental competitiveness in these two variables. The main conclusions of this paper are as follows:

First of all, through the study, it was found that all dimensions of entrepreneurs' social capital are significantly positively correlated with enterprise growth performance. This shows that entrepreneurs, as the bridge between enterprises and the external resources to communicate and contact, the essence of their work is to try to build, operate, and maintain a variety of social networks inside and outside the enterprise. Entrepreneurs should pay attention to the importance of social capital for the improvement of enterprise growth and performance, strengthen the cultivation of entrepreneurs' sense of cooperation with external interconnection, actively expand their own social network, attract a wider range of social capital, and play an important role in promoting the development and performance improvement of enterprises.

Secondly, the study also found that environmental competitiveness plays a positive moderating role in the relationship between entrepreneurs' business social capital and firm growth performance. With the strengthening of environmental competitiveness, the promoting effect of entrepreneurs' commercial social capital on enterprise growth performance will also be gradually enhanced. This indicates that when the environmental competition becomes increasingly fierce, the scarcity of various resources and the intensity of competition among enterprises will gradually rise, and the market will enter into an environment with higher efficiency, lower price and less marginal profit. Entrepreneurial commercial social capital can help enterprises obtain scarce and valuable resources from the business relationship network embedded by entrepreneurs, and carry out cooperation based on good business trust and reciprocal relationship, so as to achieve precise production, reduce costs, and improve corporate income in the competitive market environment.

Due to various conditions, this study still has the following limitations and research prospects:

First, the sample for this study only selected some small and medium-sized enterprises in the three southern provinces of China. There is a certain degree of one-sidedness in geographical distribution, so the universality of the conclusions of this study needs to be further verified. Future research can 
investigate more regions. If the sample can cover the provinces of central and eastern China, there will be more sufficient evidence for research.

Second, the accuracy of variable measurement is the prerequisite and basis for data analysis to obtain scientific conclusions. This study uses questionnaires to measure entrepreneurial social capital and corporate growth performance. Although many existing studies basically adopt this form of measurement, the lack of data sources is obvious and has a certain degree of subjectivity. Future research can consider expanding this research by combining in-depth interviews, case studies, and comprehensive analysis combined with corporate panel data.

Third, this article starts from the dimension of entrepreneurial social capital resources to study the impact of entrepreneurial social capital on corporate growth performance. Corporate growth performance may also be affected by other related variables of entrepreneurial social capital, such as structural dimensions. Follow-up research can continue to study the impact of different entrepreneurial social capital dimensions on the choice of innovation strategies.

\section{References}

[1] D. A. Smitha, F. T. Lohrkeb, Entrepreneurial network development: Trusting in the process, Journal of Business Research, (2008), Vol.61, No.4, pp.315-322, https://doi.org/10.1016/j.jbusres.2007.06.018

[2] C. Y. Jiang, S. M. Zhao, The Relationship between Social Capital, Company Enterprise and Company Performance; the Medium Role of Organizational Learning-a Case Study of the New and Developing Enterprises in Jiangsu and Guangdong, Management World, (2006), No.10, pp.90-99, 171-172

[3] D. Miller, P. H. Friesen, Strategy-making and environment: the third link, Strategic Management Journal, (1983), Vol.4, No.3, pp.221-235, https://doi.org/10.1002/smj.4250040304

[4] H. Westlund, R. Bolton, Local social capital and entrepreneurship, Small business economics, (2003), Vol.21, No.2, pp.77-113, https://doi.org/10.1023/A:1025024009072

[5] M. W. Peng, Y. D. Luo, Managerial ties and firm performance in a transition economy: The nature of a micro-macro link, Academy of Management Journal, (2000), Vol.43, No.3, pp.486-501, https://doi.org/10.2307/1556406

[6] P. P. Yang, Z. P. Yuan, Analysis on the Mechanism of Entrepreneur's Social Capital Affecting Enterprise's Dynamic Capabilities: Taking Private Technology Small Enterprises as an Example, Information Magazine, (2008), No.9, pp.146-150, https://doi.org/10.3969/j.issn.1002-1965.2008.09.043

[7] X. Geng, T. Q. Zhang, The Impact of Entrepreneur's Social Capital on Organizational Dynamic Capabilities: Taking Organizational Abundance as a Moderating Variable, Management World, (2010), No.6, pp.109-121, https://doi.org/10.1007/978-1-4419-5731-3_2

[8] P. D. Olson, D. W. Bokor, Strategy process-content interaction: Effects on growth perf, Journal of small business management, (1995), Vol.33, No.1, p.34.

[9] R. Chaganti, P. G. Greene, Who are ethnic entrepreneurs? A study of entrepreneur sapos; ethnic involvement and business characteristics, Journal of small business management, (2002), Vol.40, No.2, pp.126-143, https://doi.org/10.1111/1540-627X.00045

[10] Y. W. Jiang, Research on the Growth of Technological SMEs Based on Private Equity Investment, Modern Management Science, (2011), No.3, pp.88-90, https://doi.org/10.3969/j.issn.1007-368X.2011.03.030

[11] J. E. Ettlie, W. P. Bridges, Environmental uncertainty and organizational technology policy, IEEE Transactions on Engineering Management, (1982), Vol. EM-29, No.1, pp.2-10, DOI: 10.1109/TEM.1982.6447460

[12] J. J. P. Jansen, D. Vera, M. Crossan, Strategic leadership for exploration and exploitation: The moderating role of environmental dynamism, The Leadership Quarterly, (2009), Vol.20, No.1, pp.5-18, DOI: https://doi.org/10.1016/j.leaqua.2008.11.008 
[13] R. A. Baron, J. T. Tang, The role of entrepreneurs in firm-level innovation: Joint effects of positive affect, creativity, and environmental dynamism, Journal of Business Venturing, (2011), Vol.26, No.1, pp.49-60, https://doi.org/10.1016/j.jbusvent.2009.06.002

[14] L. X. Guo, C. M. Chen, Entrepreneur's Social Capital and Enterprise Performance: Taking Strategic Decision Quality as an Intermediary, Economic Management, (2012), Vol.12, pp.43-51, https://doi.org/10.19616/j.cnki.bmj.2011.12.008

[15] J. J. Wu, Y. Dai, Entrepreneur Social Network, Organizational Ability and Cluster Firm Growth Performance, Chinese Journal of Management, (2013), Vol.10, No.4, pp.516-528, https://doi.org/10.3969/j.issn.1672-884x.2013.04.006

[16] B. Antoncic, R D. Hisrich, Intrapreneurship: Construct refinement and cross-cultural validation, Journal of business venturing, (2001), Vol.16, No.5, pp.495-527, https://doi.org/10.1016/S0883-9026(99)00054-3

[17] G. D. Bruton, Y. Rubanik, Resources of the firm, Russian high-technology startups, and firm growth, Journal of business venturing, (2002), Vol.17, No.6, pp.553-576, DOI:10.1016/S0883-9026(01)00079-9

[18] L. L. Ji, Research on the relationship between corporate entrepreneurship and growth performance: the impact of environmental uncertainty and dynamic capabilities, Zhejiang Gongshang University, Master's Thesis, (2012)

[19] C. Lin, P. Lin, F. Song, Property Rights Protection and Corporate R\&D: Evidence From China, Journal of Development Economics, (2010), No.93, pp.49-63, https://doi.org/10.1016/j.jdeveco.2009.04.006

[20] G. Q. Chen, X. H. Wang, Organizational learning and organizational performance: the moderating effect of environmental dynamics, R\&D Management, (2012), Vol.24, No.01, pp.52-59, https://doi.org/10.3969/j.issn.10048308.2012.01.008 